\title{
Science as Interdisciplinary Analysis of Temporary and Unstable Features, and Norbert Elias' Relational Perspective of Fear, Violence and State
}

\author{
Leida Ruvina \\ PhD Candidate, University of New York Tirana (UNYT) \\ Researcher, Institute of Advanced Studies Koszeg (iASK)
}

\section{Abstract}

This article aims to reflect on some views on science by Social Theory and Cultural Analysis, which have had their resonance across the biological, physical and social sciences on the topic, without easily fitting into the dominant sociological tradition. For this purpose, the focus of the analysis is upon the contributions made in social theory and cultural analysis by the American anthropologist Clifford Geertz as opposed to the logical positivism, and by the German sociologist Norbert Elias as confirmed by the Belgian physical chemist Ilya Prigogine. By defining culture as a shared system of intersubjective symbols and meanings, a science of culture has been considered in terms of interdisciplinary analysis of temporary and unstable features; little-predictable at all levels of physical evolution, social organization, and psychological process. In contrast to classical science, whose views emphasized stability and order, Elias has found in nature the relations between biological, physical and cultural processes and to him that explains how nature, society, and individuals are interdependent with each other. By analyzing Elias' view on science, I will identify the strengths and limitations of his Figurational Sociology, where the real investigation to capture long-term figurational dynamics and developments is achieved only with the right degree of detachment from (rather than involvement into) social life and political commitment. The civilizing process remains the perfect object to study the relationship among power, knowledge, emotion, and behavior over time. The concept of civilization as a matter of perception, of natural science as temporary, strongly influenced by the external environment, and shaped by cultural receptivity to its dominant ideas, may be of particular interest in terms of policy evaluation and management of the res publica. Elias' relational perspective of fear, violence, and state is vital in the 
processual approach to the formation of class, caste, and of urban space. And rather than a laudatory or carpingly nihilist speech-which history shows it can foster cruel behaviour across a nation- critical thinking should be seriously considered and encouraged by experts of media, academia and political communication, to avoid potential barbarisms in the twenty-first Century, in developing, second or first world countries.

Keywords: Social Theory, Cultural Analysis, Science, Decivilization, Figurational Sociology, Norbert Elias

\section{Views of Science: Geertz' Analysis of Culture versus Logical Positivism}

Logical positivism did not die with the dispersal of Vienna circle members, nor their arrogantly proposed idea on the elimination of experience and metaphysics. Other terms like logical empiricism or quantitative research defined the same view on science: a rational reconstruction of all things since all things would be measurable. No explicit theoretical or philosophical commitments should scientists provide, no abstract ideas or laws should be considered, beyond the ones observed. Ignoring the sense experience as the once only source of knowledge, in order to find logical meaning, the new empiricism focused instead exclusively on empirical statements of what is observed and on logical-mathematical analysis of what is already known. The decision-making would depend on these quantitative, statistical, mathematical data. Hence, science (natural and social) would be defined in such terms by an adversary process (where Baconian observers, through a scientific method, battle ideas with tools of observation and data); by an advocacy process (where Popperian falsifiers, through the falsification theory, defend what is right as in a court of law); and a peerreview process (where Kuhnian revolutionaries, through paradigm shifts, separate nonsense from valid science). And social science (just like science) would have three goals: describe, control, predict.

Postpositivist (such as the Austrian-Belgian philosopher Karl Popper, or the American philosopher Thomas Kuhn) and critical theory authors (as the neo-Marxist Frankfurt School) opposed to this view of science in search of laws, preferring the understanding of the inner nature of social phenomena which are not measurable nor expressed in quantitative terms. What could culture be if not a semiotic matter, working on how cognition works? What could culture be composed, if not of psychological structures-or 'web of significances' according to Weber-through which groups and individuals guide their behavior? How could culture consist of radical 
behaviorism only, without observing step by step action, behavior, culture, and its inference and implication in defining the gesture? How can a cultural analysis ignore that acts are signs? And that interworked systems of construable signs compose a culture, a context, thickly described?

In such terms, rather than a science looking for a law, the American anthropologist Clifford Geertz, one of the opponents of the logical positivism, in his selected essays published in The Interpretation of Culture in 1973, defined the analysis of culture as an interpretative science in search of meaning. An evaluation of that meaning, otherwise known as thick description, is what Geertz focused on in the first chapter of his work. ${ }^{1}$ Refusing the methodological dogma of Skinnerian behaviorism or the intelligence testing, forgetting the generalization across cases through the coding of abstract regularities, and not attempting to subsume observations under a governing law, Geertz then applied techniques and received procedures, such as as keeping a diary, taking genealogies, providing reports, selecting informants, transcribing text, committing himself-such as every anthropologist and ethnographer should-into an intellectual effort. Opting for an emic approach supposes that anthropologist writings are interpretations (nor statistics), his/her own constructions of others' construction on whom they think they and others are. Only after the observational activity, may begin the interpretative activity on symbols, not studied for the sake of it but for what they mean to others and reveal about culture.

The goal of cultural analysis and anthropology is then the enlargement of the universe of human discourse, its analysis, the redefinition of a debate not the report of conclusions. Ethnography does not refer to the verification criteria, nor it is predictable; anthropology hypotheses are not scientifically tested and approved. The cultural analysis is guessing meanings, assessing the guesses, drawing explanatory conclusions from the better guesses.

If, as the logical positivism presumes, human nature was clear, simple, "natural, universal, and constant", then the consensus gentium about a single human nature (independent of time, place and circumstances) would have produced substantial universals-but it actually does not. Unlike Enlightenment and Classical anthropology, human nature is today seen as "conventional, local, variable" to cultures. According to Geertz, culture may be seen as a second nature of humans, in search of a systematic relation between phenomena. Anthropology is not biology, yet it integrates biological, psychological, sociological and cultural factors as variables within unitary systems of

1 Geertz, Clifford (1973). "Thick Description: Toward an Interpretative Theory of Culture", in The Interpretation of Culture: Selected Essays, Basic Books Inc. Publishers, New York, pp. 3-32. 
analysis. Culture, Geertz states, is the number of culture patterns, of specific (rather than general) organized systems of significant symbols which govern human mass behavior and prevent it from being a chaos of exploding emotions, pointless acts or absent intellect.

The contribution of Geertz stood in affirming (i) the interaction between the physical evolution and the cultural development, denying the stratigraphic traditional view where one phase preceded the other; (ii) the biological changes toward modern man, occurring especially in the brain; and (iii) the man as unfinished animal and cultural artefact, whose evolution stands not on his ability to learn but how much and what he has to learn before to function at all.

Man is then defined not only by his innate capacities-as claimed during Enlightenment, neither by his actual behaviour-as stated in contemporary social sciences: man is the link of both, through the culture that shapes us individually. Culture, according to Geertz, is characterized by a social phenomenon and shared system of intersubjective symbols and meaning, while a science of culture lays its road to the general, through a concern with the particular and circumstantial, in terms of interdisciplinary analysis of the physical evolution, the functioning of the central nervous system, social organization, psychological process, and cultural patterns.

\section{Norbert Elias' View on the Civilizing Process versus Prigogine}

A new view on science had its resonance across biological, physical and social sciences. In his human power related theory of 1939, Elias conceived the temporality of natural science-a conception overtaken in 1984 and 1997 by the complex theory of the Belgian physical chemist Ilya Prigogine, who observed instability, multi-choices, fluctuations, and little predictability at all levels. In contrast to the classical science whose views emphasized stability and order, Elias observed that relations between biological, physical and cultural processes are found in nature and this is how nature, society, and individuals are interdependent with each other. ${ }^{1}$

Elias' name is closely related to historical studies and social development at the center of the sociological thought. Through his radical approach to sociology, the historical roots of modern societies, forms of social interaction and social identities have been analyzed, interconnecting the development of psychological life and emotion with the processes of a larger scale, such as the state formation, urbanization and economic development, therefore integrating different national traditions and disciplines perspectives, as noted by the Australian professor of Sociology Robert van Krieken.

${ }^{1}$ Elias, Norbert (1992). Time: An Essay, Blackwell, Oxford, p.16. 
In the 1939's German edition of The Civilizing Process: Sociogenetic and Psychogenetic Investigations, Elias explained that it was in this historicization of human psychology that he provided empirical support of the combination of social relations change with a psychic structure change, and the civilizing process was the perfect object to study the relationships among power, knowledge, emotion, and behavior over time.

But what was Elias' view on the civilizing process?

In The Court Society, first published in 1969 and based on his 1933 docent thesis, Elias has identified the royal and aristocratic courts of the seventeenth century European societies-rather than towns or cities-as origin of the bourgeois and capitalist societies: it was on that particular psychic structure of the court and its particular mode of conduct that the bourgeoisie habitus was based.

A second observation was the court rationality as a precursor to both the legalrational bourgeois rationality and its foundation. While the professional bourgeoisie calculated the financial gain and losses (the economic capital) as the predominant opportunity for power, in the previous court societies it was the position, the status and the prestige (so the symbolic capital) that defined the winner or the loser. The highly competitive and constantly fluctuating performance of the exhibition of this status and prestige made the entire individual existence and identity a representative one. While in bourgeois societies social constraints depend on work and the private life depends on the professional status, in the previous court societies private life was not divided from the public one, because at any time, any place, the management of emotions in the ritual etiquette defined the social success or failure. Authenticity and free expression of the own emotional character was at all costs to be avoided, substituted with specific forms of self-observation, complementary to the observation of others. According to the symbolic interaction argument, the (incalculable) prestige perceived and defined as real, had real (and calculable) consequences.

The third observation that Elias offered on court societies, regarded the continuing power of particular mechanisms and social differentiation in the contemporary social life. While bourgeois rationality established a clear distinction between private and public life and defined work success as criteria for the self-success, the social prestige (as informal organizational structure and culture of court society) is not a matter of the past: its representation is still important today, as long as the supposed social superiority is real only if others recognize it. And it doesn't take a King or nobles to understand, apply or evaluate that. 
In The Civilizing Process, originally published in 1939, Elias' observed the development of modern social life, focusing on the central factor of the contemporary psychic structure of European societies: the self-perception of Europeans as particularly 'civilized', during the Middle Ages barbarisms. Elias considered the medieval era as the starting point of the development curve to the modern age. In his view, the human conduct at that time was naïve, simple, and the own emotional character was expressed directly and violently. Ideas were simple too, psychological nuances were fewer. The sophistication of standards arrived later when the limits of shame, embarrassment, and repugnance increased considerably. ${ }^{1}$ To understand the relation between the social process and the psychical process (defining so the later as changeable rather than static), Elias explored a variety of nineteenth century etiquette manuals.

The second concern regarded the investigation of the specific social processes that cause psychic change (suggesting the interdependence of the psychic change and the broader social relationships). Ferocity and murders dominating the medieval everyday life were rarely subject to self-control, neither to asocial one: torture and sadism were instead considered extreme pleasures from the society. In the following court society which actually imposed a greater regulation of violence and a firmer constrain, control, suppression of impulses and emotions, the behavior code was based on the long-term requirements of complex social interaction networks. That's how through the internalization of this code behavior (rather than the direct physical force) it was given life to a new era of courtesy and representation, and so, to the concept of civilization. And just like the psychological perception gave form to the civilizing process, the civilizing process transformed the whole drive, affected the economy and areas of conduct: the interdependence of understanding our actions, others' actions and the consequences correlated, increased the self-regulation (psychologization and rationalization). To investigate this second point, Elias explored the history of the $17^{\text {th }}$ and eighteenth century state-formation in Germany, France, Great Britain, especially the state monopolization of violence. To the critics, he answered that civilization is not only a process but a never-ending one.

In The Germans, originally published in 1989, Elias focused further on the instability trait of civilization in which human drives play its opponent but also its basis. By expliciting the theoretical principle according to which desires and emotions are

\footnotetext{
1 For the crucial impact of shame and embarrasement in human nature see also Thomas J. Scheff, "Elias, Freud and Goffman: Shame as the master emotion", in Steven Loyal and Stephen Quilley eds. (2004). The Sociology of Norbert Elias, Cambridge University, New York, pp. 229-242.
} 
socially constituted, Elias' analysis posed a continuous development process-rather than distinct historical ones.

First, the German case was chosen for the historical national identity formation, investigating how processes of civilization and decivilization interrelate within the development of any nation-state and within its state members' habitus. ${ }^{1}$ Elias' argument was that brutalized behavior within civilized societies may occur, but it requires considerable time, long enough to decompose the individual conscience. The Nazis Germany was the example of how nationalism played a crucial role in the individual identity and self-perception, making the individual personality structure, the conscience formation, and the code of behavior attuned with that regime. The critical thinking was minimal, the abilities to make independent judgments were limited, and the individual conscience was weak.

Secondly, in the ambivalent and contradictory character of civilization processes, Elias observed the question of the so called civilized barbarism. His argument suggested that specific state-forming processes may produce either a deficient civilization process or a decivilizing manifestation of brutal and violent behavior; both civilization and decivilization may occur simultaneously (as in the Nazis German regime, the same social norms that produced integration among some people turned out to divide and exclude them from others).

Third, through the informalization process, Elias observed how an increased moderation and self-restraint can be manifested once norms of various human activities are amused. This individual 'second nature' of social restraint happens wherever social rules and sanctions partially lose their significance and a more informal attitude to manners and etiquette is noticed (as in Germany after the World War II). The more declined the importance of a code behavior, the greater the perception of individual 'freedom', the greater the demand for self-management and self-compulsion.

Forth, for Elias, the Mannheim's generational problem (the relation between generations) is seen as a vehicle to a better understanding of social change processes. Comparing the groups of German right-wing youth in the 1920-30s with the German left-right terrorists in the 1960-70s, Elias argument was that social change depends not on the youth's desires only, their needs and acts, as much as on the particular historical configuration that allows a particular critical understanding and ethical

${ }^{1}$ van Krieken, Robert (2005). Key Sociologist: Norbert Elias, Routledge, London, p. 103. 
stance for the young people. The main arguments Elias developed was that most of the times, for the young generations, the structure of opportunity remains unplanned and uncontrolled consciously; and that barbarism and civilization are a vicious circle (modern barbarism is produced by particular social figurations and socio-historical development processes, as its critical responses are produced from a particular development of the modern state).

To conclude, Elias' conception of science was that of a social institution, through which individuals' interdependencies, individuals' relations (rather than static states), long-term processes of change and development (rather than timeless conditions), social-emotional involvement and a detachment from the object of study, and a consciousness that the combinations of intentional actions is mostly unplanned and unintended, can all answer to the question: what it is like to be a human being.

His emphasis was on the relation between social change and psychological development (sociogenesis-psychogenesis) in micro and macro levels of sociological analysis, but that missing prediction of individual or social actions (and relative turbulence, instabilities, disequilibrium as characteristic of human life) was an observation Prigogine made years after. In the foreword of Prigogine's Out of Order and referring to the author's view, science was defined not as an independent variable but « ... an open system embedded in society and linked to it by very dense feedback loops. It is powerfully influenced by its external environment, and, in a general way, its development is shaped by cultural receptivity to its dominant ideas ... ».1

Challenging the Newtonian model, Prigogine sustained that the so-called universal laws were not universal at all, but applicable to some local regions of reality only. Rather than uniformity, equilibrium, stability, and order of industrial societies, the transition to high-tech societies through accelerated social change was characterized by diversity, disequilibrium, instability, and disorder, by unplanned non-linear relationships that could provoke massive consequences for the smallest inputs.

In distinguishing biology and physics, Prigogine drew the possibility of their coexistence rather than contradiction, implying a deep synthesis of a new relationship between chance and necessity - with proper social, political extension and analogies with social and historical phenomena. In his book Order Out of Chaos, he was projected into the contemporaneous revolutionary world made of turbulences, instabilities, disequilibrium. Prigogine insisted on the importance of keeping open the

\footnotetext{
1 Toffler, Alvin (1984). "Foreward”, in Ilya Prigogine and Isabelle Stengers (1984). Order out of Chaos: Man's New Dialogue with Nature, Bantam Books, New York, p.xii.
} 
communication channels between Society and Science, since the Western science born in the seventeenth century (through the experimentation and the scientific method as new methodological considerations), now develops into another cultural context and environment. Still, the fundamental laws remain elusive: there are evolution and diversification in all the levels observed, and while primary laws help to describe basic processes of passive matter and single particles in a mechanistic world view, secondary laws are used to describe the system as a whole, the active, fluctuating matter.

\section{Strengthens and Limitations of Elias' Figurational Sociology}

Elias' strength stood in his empirical historical studies. But his theoretical position was complex as well, from his conceptual arguments such as The Civilizing process, to explicitly theoretical works such as What is Sociology or The Society of Individuals.

By embedding his theory into his method and sociological practice, Elias aimed to elaborate a comprehensive theory of human society where all his conceptual arguments were linked with the others; the development of a humanity theory through an integrating framework as social sciences reference.

Although he preferred "process sociology" to the term "figurational sociology", the label was yet inadequate (as long as it suggested that a 'non-process sociology' is possible). Eliasian arguments do not constitute one approach among many, and so they do not adopt a pluralist position: they rather suggest how sociology itself should be approached.

To Loyal and Quilley, editors of a comprehensive introduction to the sociology of Norbert Elias, he «lays the basis for a historical and comparative understanding of the relationship between 'front' and 'backstage', as well as the corresponding psychical structures and the figurational matrices to which these relate». ${ }^{1}$ Through an equally historical, psychological and sociological study, he succeeded where Watson's behaviorist psychology, Cannon's physiology, Fred's psychoanalysis and Kohler and Wertheimer's 'Gestalt theory' failed. In The Civilizing Process, for example, Elias showed how the Freudian superego has developed through time and space, examining the historical transformations of sleeping patterns in the 'presentation of the self', and how they were related to specific emerging structures of social interdependence.

\footnotetext{
${ }^{1}$ Loyal, Steven and Stephen Quilley eds. (2004). The Sociology of Norbert Elias, Cambridge University Press, New York, p. 4.
} 
Elias' legacy stands in the deceptive propositions, or defining features, of its figurational approach. (I) Interdependence of human relationships: the dynamic nature of the humans' social figurations (formed with each other) cannot be bounded to individual motivations or actions, the individual process of development and growth, as well as the direction of individual lives, depends on such emergent dynamics. (II) Constant flux and transformation of social figurations with interweaved processes of change in various but interlocking time-frames. (III) Unplanned and unexpected character of long-term transformations of human social figurations. (IV) Within such figurations takes place the human knowledge development-sociological knowledge included. The figurational approach constitutes the complex link between Elias's theory of knowledge and the sociology of knowledge processes. ${ }^{1}$

These propositions are the basis for the Eliasian warrants to contemporary sociologists, such as Quilley in 2005.

Stop studying single individuals, humanity or society as static entities! Avoid the debated dualism between the micro-macro perspective of individual vs. society, or structure vs. agency. The macro-level (processes of state formation and extension in the scale and scope of human interdependencies-sociogenesis) is connected with the micro-level (processes of individual socialization and personality and habitus formation-psychogenesis).

Pass from homo clausus (and the perspective underlying all methodological individualism) to homines aperti (orientation toward pluralities of 'open people'). The nature of any individual's psychology depends on the figurational matrices (dynamic configurations that individuals form with each other).

And the 'figurations' concept applies alike to interdependencies between small groups of individuals and large groups associated with classes, race and caste, cities, nation-states, and entire humanity.

Avoid the mind-body philosophical duality and filter it into much sociological theorizing! Sequences of long-term processes of civilizing are equivalent to long-term transformations in the pattern of personality formation and individual socialization. Concepts of psychogenesis and homines aperti are parallel to Mead and Goffman's interactionist understanding of the self. In line with this, the 'second nature' concept aims at the creation of historically located groups of 'interdependent selves'.

${ }^{1}$ Goudsblom, Johan (1977), Sociology in the balance, a critical essay, Blackwell, Oxford, pp .6-8. 
Avoid the dominant conceptual vocabulary that reduces (dynamic) processes to (static) states! There are no social structures outside the 'figurational flux'. And the enormous potential of Elias' "functional sociology" applies to sociology of class and race, sociology of organizations, informalization processes, processes of state formation, nationalism, gender, sexuality, religion, art and aesthetics, (de)civilizing processes, crime and punishment, sports and leisure activities, food, drugs or alcohol and tobacco use, medicine and psychoanalysis, animal-human relation, as noted by British sociologists Dunning and Mennell in 2003.

Avoid the separation object-relationships! Develop a relational understanding of social forms, without thinking in absolute functions and values.

See sociology in terms of preserving efforts people do to direct themselves within the social figurations formed with each other! (as suggested by the Nonprofit Management professor Nidhi Srinivas in 2005). In his 1987's Involvement and Detachment, Elias underlined that real investigation to capture long-term figurational dynamics and developments is achieved only with the right degree of detachment from (rather than involvement into) social life and political commitment.

Particularly important was the Eliasian relational perspective of fear, violence, and state in the processual approach to the formation of class, caste, and urban space. According to him, when public institutions collapse and the welfare 'social safety net' is substituted by the 'dragnet' of police, courts, and prisons, there is to be found the political root of the urban patterning of racial and class exclusion of which the today hyper-ghetto is the concrete materialization. ${ }^{1}$

To Elias, the epicenter of the modernity experience is first made by fear as a central mechanism for the social control interjections and the self-administered 'regulation' of the entire instinctual and collective life (in the case of the American ghetto, the fear was about contamination and degradation through the association with 'inferior beings' - African slaves). And second, by violence as a critical tool in remodeling the social and symbolic boundaries. (In the ghetto case, violence came from below as interpersonal aggression and terror, or from above as state-sponsored discrimination and segregation).

\footnotetext{
1 Wacquant, Loïc (2004). "Decivilizing and Demonizing: The remaking of the Black America ghetto", in Steven Loyal and Stephen Quilley (eds), The Sociology of Norbert Elias, Cambridge University Press, New York, p. 95.
} 
Warning against Zustandreduktion or 'reduction of processes to state' into the idiom of poverty research, Elias did not opt so for descriptive properties of disadvantaged individuals or population-as the positivist philosophy induces. Instead of the variable-oriented social analysis, he applied the extending web of interdependent persons and institutions-as the figurational sociology suggests. And rather than the separated macro-structures and micro-formation, Elias pointed at the biopsychosocial constitution of the individual, suggesting that sociogenesis and psychogenesis are two sides of the same coin of our existence: if one changes, the other is affected inevitably. ${ }^{1}$

And it is through the figuration concept that the pre-Elias sociology would break out of the nonlinear, static, dehistoricized picture of reality, with the standard onedimensional ladder model of the class image. ${ }^{2}$ In the words of the Icelandic sociologist Jóhann Páll Árnason in 1987 «Elias relationship to the sociological traditions and to its contemporary offshoots can be described in terms of six antitheses: his approach is antieconomistic, anti-normativistic, anti-reductionistic, anti-functionalist, anti-structuralist and anti-individualistic». ${ }^{3}$

According to the London School of Economics sociologist, Nicos Mouzelis, something went wrong with sociological theory as a whole, or better with the 'post-Parsonian sociological theory' of the last two decades. Emerged since the 1960s, new sociologies' types have faced criticism: Goffman and ethnomethodologists' interpretative sociologies fail at the macro level; Foucault and Baudrillard's postmodernism (poststructuralism included) were not the answer; Coleman's rational choice theory is rejected for reasoning too deductively; neo-functionalism is rejected for being too arbitrary in amending the 'social system' concept of Parson; Bourdieu and Giddens wished they went beyond the dichotomy subject-object. And the agency-structure problem was not solved in Elias' 'figurational sociology'. After so much anarchy and cacophony between paradigms in the today sociology, functional prerequisites need to be reconstructed if we want a social system to exist, states Mouzelis in 1995.

British sociologist Eric Dunning, founding father of the sociology of sport, and Chris Rojek, influential professor in leisure studies, in their 1992's Sport and Leisure in the Civilizing Process: Critique and Counter-Critique, praised Elias's contributions to

\footnotetext{
1 Wacquant, 2004, pp. 111-112.

2 Loyal, Steven (2004). "Elias on class and stratification", in Loyal and Quilley (eds), The Sociology of Norbert Elias, Cambridge University Press, New York, p. 139.

3 Árnason, Jóhann Páll (1987). "Figurational sociology as a counter-paradigm", in Theory, Culture \& Society, Vol.4, No.2, p. 429.
} 
sociology, extending his conceptual tools of figurational sociology to the explanation of the complex evolution and bureaucratization of sport and leisure activities in modern societies (conceptual tools more adequate than the ones from rival approaches like cultural studies, feminism, neo-Marxism, discourse analysis). Yet among functional sociology theory and opposing paradigms, there is missing bridging and communication between, they noted.

If human behavior has 'a second nature,' its 'automated' aspect is due to the cluster of meaning we attach to everyday concepts, and in sociology according to Elias a certain detachment from the behavioral assumptions is required. Believing the problem stood in the categories and concepts that organize human behavior and society, and being concerned in developing a different perception of the social world, in his 1969's contribution "Sociology and psychiatry", Elias suggested a particular conceptual framework and sociological vocabulary. ${ }^{1}$ It is in this light that standard concepts (used in the first half of the twentieth century by most sociologists) saw radical alternatives that, according to Elias, could get closer to the reality:

\begin{tabular}{|ll|l|}
\hline $\begin{array}{l}\text { Standard sociological concepts in } \\
\text { the first half of the twentieth } \\
\text { century: }\end{array}$ & $\begin{array}{l}\text { Radical alternative concepts for } \\
\text { contemporary sociologists: } \\
\text { Role }\end{array}$ & $\begin{array}{l}\text { Figuration } \\
\text { Process }\end{array}$ \\
Society & Interaction & Habitus \\
Structure & Individual & Civilization \\
System & Reproduction & Relation \\
& & \\
\hline
\end{tabular}

But, as Elias would note in The Society of Individuals in 1991, there was a problem in exercising this frame: the main partial and temporary nature of all Elias' concepts, whose contingency with any given empirical evidence would define their validity. ${ }^{2}$

And that sense of intellectual dissociation by developing his ideas in a singular manner with scant reference to his contemporaneous, that empirical and historical methodology and a direct style of writing combined with his detachment from the

\footnotetext{
1 Elias, Norbert (1969). "Sociology and psychiatry", in S. H. Foulkes and G. Stewart Prince (eds),

Psychiatry in a Changing Society, Tavistock Publications, London, p. 127.

2 Elias, Norbert (1991). The Society of Individuals. Oxford: Blackwell, Oxford, p. 32.
} 
immediacy of political commitment, were another reason why Elias explanatory power and originality did not fit easily into any dominant sociological tradition.

\section{Conclusions and recommendations}

The objective of this paper is to reflect on some views on science, that have had their resonance across the biological, physical and social sciences on the topic, without easily fitting into the dominant sociological tradition. For this purpose, the focus of the analysis is upon the contributions made in social theory and cultural analysis by the anthropologist Clifford Geertz, as opposed to the logical positivism, and by sociologist Norbert Elias, as confirmed by Ilya Prigogine.

By defining culture as featured by the social phenomenon and as a shared system of inter-subjective symbols and meanings, a Science of Culture has been considered in terms of interdisciplinary analysis of temporary and unstable features; littlepredictable at all levels of physical evolution, social organization, and psychological process. In contrast to classical science, whose views emphasized stability and order, Elias has found in nature the relations between biological, physical and cultural processes and to him that explains how nature, society, and individuals are interdependent with each other.

By analyzing Elias' view on science, I have identified the strengths and limitations of his Figurational Sociology, where the real investigation to capture long-term figurational dynamics and developments is achieved only with the right degree of detachment from (rather than involvement into) social life and political commitment. The civilizing process remains the perfect object to study the relationship among power, knowledge, emotion, and behavior over time. The concept of civilization as a matter of perception, of natural science as temporary, strongly influenced by the external environment, and shaped by cultural receptivity to its dominant ideas, may be of particular interest in terms of policy evaluation and management of the public thing. Elias' relational perspective of fear, violence, and state is vital in the processual approach to the formation of class, caste, and urban space. And rather than a laudatory or carpingly nihilist speech - which history shows it can foster cruel behaviour across a nation - encouraging critical thinking should be seriously taken into consideration by experts of media, academia and political communication, to avoid potential barbarisms in the twenty-first Century, in developing, second or first world countries. 


\section{References}

[1] Arnason, Jóhann Páll (1987). "Figurational sociology as a counter-paradigm", in Theory, Culture \& Society, Vol.4, No.2, pp.429-456.

[2] Dunning, E. and Rojek, C. eds. (1992). Sport and Leisure in the Civilizing Process: Critique and Counter-Critique, London: Mcmillan. Reviewed also by Mouzelis, N. (1993) "On Figurational Sociology", in Theory, Culture \& Society Vol.10, London, Newbury Park and New Delhi: Sage, pp.239-253.

[3] Dunning, E. and Mennell, S. (2003). Norbert Elias: Sage Masters of Modern Social Thought, 4 vols. London: Sage.

[4] Elias, Norbert. (1969). "Sociology and psychiatry", in Foulkes, S.H. and Prince, G.Stewart Prince eds. (1969) Psychiatry in a Changing Society, London: Tavistock Publications, p.117-144.

[5] Elias, N. (1983). The Court Society. Oxford: Basil Blackwell. Originally published as Elias, N. (1969) Die höfische Gesellschaft, Darmstadt and Neuwied: Hermann Luchterhand Verlag.

[6] Elias, N. (1987). Involvement and Detachment, Oxford: Blackwell.

[7] Elias, N. (1991). The Society of Individuals. Oxford: Blackwell.

[8] Elias, N. (1992). Time: An Essay. Oxford: Blackwell.

[9] Elias, N. (1996). The Germans. Power Struggles and the Development of Habitus in the Nineteenth and Twentieth Centuries. Cambridge: Polity Press. Originally published as Elias, N. (1989) Studien über die Deutschen, Frankfurt am Main: Suhrkamp Verlag.

[10] Elias, N. (2000). The Civilizing Process. Sociogenetic and Psychogenetic Investigations, Revised edition. Oxford: Blackwell. Originally published as Elias, N. (1939) Über den Prozess der Zivilisation, 2 vols. Basel: Haus zum Falken.

[11] Geertz, C. (1973). The Interpretation of Culture. Selected Essays. New York: Basic Books, pp.3-55.

[12] Goudsblom, J. (1977). Sociology in the balance, a critical essay, Oxford: Blackwell, pp.6-8.

[13] Krieken, Robert van (2005). Key Sociologist: Norbert Elias. London: Routledge.

[14] Loyal S. and Quilley, S. eds. (2004). The Sociology of Norbert Elias, New York: Cambridge University Press.

[15] Mouzelis, N. (1995). Sociological Theory: What went wrong? Diagnosis and Remedies, London and New York: Routledge.

[16] Prigogine, I. and Isabelle S. (1984). Order Out of Chaos. Man's new dialogue with nature. New York: Bantam Books. 
[17] Prigogine, I. (1997). The End of Certainty: Time, chaos and the new laws of nature. New York: Free Press.

[18] Quilley, S. (2005). "Eliasian Sociology as a 'Central Theory' for the Human Sciences”, in Current Sociology, Vol. 53 no.5, pp.807-828.

[19] Srinivas, N. (2005). "Cultivating Sociological Detachment through Reflexivity: Response to Quilley and Loyal”, in Current Sociology No.53, pp.835-841. 